\title{
A Clinical Study on Eclampsia in a Referral Hospital
}

\section{Parneet Kaur}

\section{ABSTRACT}

Objective: To analyze the cases of eclampsia in a referral hos pital, like GGS Medical C ollege, Faridkot, with special focus on booked/unbooked/referred, age, parity and antenatal care. Also fetomaternal outcome was seen in all the cases.

Materials and methods: All the cases of eclampsia referred from nearby rural areas, civil hospitals and CHC s sent here for specialist care were studied in this 2 years study from J uly 2003 to J une 2005.

Results and conclusions: A total of 50 cases of eclampsia were admitted. The incidence came out to be $7.4 \%$. Ninetyeight percent of cases were unbooked. Majority of the cases belonged to 21 to 30 years age group. Fifty-six percent of the cases were primigravida. Eighty-eight percent had no antenatal check-up at all. Thirty percent of babies were still born and $12 \%$ had early neonatal death. There were three maternal deaths. Antepartum eclampsia was most common seen in $68 \%$ of cases. We concluded that there is lack of antenatal care in rural areas and urban slums and this needs to be addressed to prevent this serious complication of pregnancy. Moreover, personnel at district hospitals and $\mathrm{CHCs}$ should be capable of administering magnesium sulfate, the anticonvulsant as none of the patient threw a fit after loading dose of magnesium sulfate.

Keywords: Eclampsia, Magnesium sulfate, Referral hospital.

How to cite this article: Kaur P. A C linical Study on Eclampsia in a Referral Hospital. J South Asian Feder Obst Gynae 2012;4(2):113-115.

\section{Source of support: Nil}

\section{Conflict of interest: None declared}

\section{INTRODUCTION}

Though by the end of twentieth century, eclampsia has become almost unknown to obstetricians in the developed countries, it still remains an important factor of maternal and perinatal morbidity and mortality in the developing countries, like India. It is estimated that every year eclampsia is associated with 50,000 maternal deaths worldwide most of which occur in devel oping countries. ${ }^{1}$ The incidence of eclampsia is still high in referral hospitals though it is a preventable complication of pregnancy. ${ }^{2}$ W ithout a doubt proper antenatal care is the most important part of prevention.

\section{MATERIALS AND METHODS}

GGS M edical College is a referral Hospital. All cases from nearby rural areas, $\mathrm{CHCs}$, civil hospitals and private nursing homes are sent here for specialist care. In this 2 years study, from J uly 2003 to J une 2005, a total of 50 cases of eclampsia were admitted. All the cases were analyzed with special focus on booked/unblocked/referred, age, parity and antenatal care. Also fetomaternal outcome was seen in all the cases. On admission, all cases were thoroughly examined and put on treatment.

- All the cases were put on Pritchard's regime giving magnesium sulfate $4 \mathrm{gm} \mathrm{I} / \mathrm{V}$ bolus dose and $5 \mathrm{gm} \mathrm{I} / \mathrm{M}$ in each buttock followed by $5 \mathrm{gm} \mathrm{1/M}$ in alternate buttock 4 hourly

- $\quad S / L$ Nifedipine was given for control of BP

- Supportive therapy in form of I/V line, suction SOS, continuous catheterization, oxygen inhalation and mouth gag, etc. was given

- After stabilization of patient, obstetrical management was carried out.

\section{OBSERVATIONS}

The incidence of eclampsia came out to be $7.4 \%$. Only one case in the study was booked (2\%). Rest all cases were unbooked $(36 \%)$ or referred $(62 \%)$ from nearby $\mathrm{CHCs}$, civil hospitals and private nursing homes (Table 1 ).

$M$ ajority of the cases had no antenatal check-up ( $88 \%)$ and were illiterate (96\%). A large number of cases belonged to rural background (80\%).

$M$ aximum number of cases was between age groups of 21 and 30 years (62\%). Twenty-six percent were below 20 years of age and $12 \%$ above 30 years.

Highest number of females was primigravida in this study (Table 2).

A ntepartum eclampsia was the commonest variety (68\%), followed by postpartum eclampsia (20\%) and intrapartum eclampsia (12\%) (Table 3).

Seventy-six percent of the subjects had vaginal delivery, $4 \%$ forceps delivery and $20 \%$ underwent lower segment cesarean section (L SCS).

\begin{tabular}{lrr}
\multicolumn{3}{c}{ Table 1: Booked/unbooked/referred cases } \\
\hline Booked/unbooked/referred & No. & $\%$ \\
\hline Booked & 1 & 2 \\
Unbooked & 18 & 36 \\
Referred (from nearby CHCs, CH, Pvt & 31 & 62 \\
nursing homes) & & \\
\hline
\end{tabular}

The one booked case was also advised admission on one of her earlier visit but she refused

\begin{tabular}{lcr}
\multicolumn{3}{c}{ Table 2: Antepartum/intrapartum cases } \\
\hline Antepartum/intrapartum & No. of cases & Age (\%) \\
\hline Primigravida & 28 & 54 \\
Multigravida & 12 & 24 \\
\hline Postpartum cases & & \\
\hline Primipara & 8 & 16 \\
Multipara & 2 & 4 \\
\hline
\end{tabular}




\begin{tabular}{lcr} 
& \multicolumn{3}{c}{ Table 3: Type of eclampsia } \\
\hline Types & No. of cases & Age (\%) \\
\hline Antepartum & 34 & 68 \\
Intrapartum & 6 & 12 \\
Postpartum & 10 & 20 \\
\hline
\end{tabular}

In our study, none of the patient threw a fit after initiation of magnesium sulfate therapy which is a very important observation.

$M$ aximum number of patients presented in third trimester of pregnancy (96\%) except $4 \%$ who had gestation of less than 28 weeks.

$M$ aternal complications occurred in the form of DIC, postpartum pyrexia, oliguria and postpartum hemorrhage (PPH), etc. (Table 4). The complication rate came out to be $38 \%$.

$M$ aternal mortality in present study came out to be $6 \%$ (Table 5).

There were $56 \%$ alive births, $30 \%$ still-births and $12 \%$ early neonatal deaths (Table 6).

\begin{tabular}{lcc}
\multicolumn{3}{c}{ Table 4: Maternal complications } \\
\hline Complications & No. of cases & Age (\%) \\
\hline DIC & 2 & 4 \\
P ostpartum pyrexia & 3 & 6 \\
P PH & 6 & 12 \\
CVA & 2 & 4 \\
P sychosis & 1 & 2 \\
Oliguria & 3 & 6 \\
Bed sores & 1 & 2 \\
Accidental hemorrhage & 1 & 2 \\
\hline Total & 19 & 38 \\
\hline
\end{tabular}

Table 5: Cases of maternal mortality

Maternal mortality: Three of our cases died because of following reasons giving maternal mortality rate of $6 \%$

\begin{tabular}{ll}
\hline Acute renal failure & 1 \\
Pulmonary edema & 1 \\
Cerebrovascular accident & 1 \\
\hline
\end{tabular}

(a) Three patients who died were referred from areas $>50 \mathrm{~km}$ away from our institution so delayed hospitalization is one main factor for maternal death

(b) All the cases had antepartum eclampsia, thus proving that antepartum eclampsia has more serious consequences

\begin{tabular}{lcc}
\multicolumn{3}{c}{ Table 6: Fetal mortality } \\
\hline Fetal outcome & No. of cases & Age (\%) \\
\hline Still-birth & 15 & 30 \\
Early neonatal death & 6 & 12 \\
Live & 28 & 56 \\
Undelivered & 1 & 2 \\
\hline
\end{tabular}

\section{DISCUSSION}

The incidence in our study came out to be $7.4 \%$ which is high as compared to other studies. The incidence seems high as compared to reported incidence in Indian referral hospitals. The reason may be that all the normal uncomplicated deliveries are being conducted at Civil Hospital, Faridkot.

Sixty-two percent of the cases were referred from nearby civil hospitals, CHCs and private nursing homes in present study which is nearly same as reported by Shaheen B et al $(66.2 \%)^{3}$

Large number of cases in our study was from rural background, illiterate, unbooked with no antenatal check-up. Similar findings were reported by Samal S et al, K hanum M et al and Chandra and B hardwaj. ${ }^{4-6}$

$M$ ajority of the cases in present study were primigravidas. Sheraz S et al (69.1\%), Datta M R et al $(66.0 \%)$ and Shaheen B el al $(69 \%)$ also reported maximum occurrence of eclampsia in primis. $3,7,8$

$M$ aximum number of cases were between 21 and 30 years of age which is comparable to Sarma HK $(71.79 \%)$ and Sheraz S et al $(78.2 \%)^{7,9}$ In our study, prevalence of antepartum eclampsia came out to be highest which is comparable to the studies of Sarna HK $(69.23 \%)$, Sheraz S et al $(67.3 \%)$ and Shaheen B et al $(62 \%))^{3,7,9}$

$M$ ost of our subjects presented with fits at term pregnancy (72\%). Similar findings were reported by Choudhary P. ${ }^{10}$

$M$ aternal mortality of $6 \%$ in present study is comparable to that of Sheraz S et al $(3.6 \%),{ }^{6} \mathrm{G}$ addi and Somegow da $(5.4 \%)^{11}$ but less as reported by Nobis PN (11.54\%). ${ }^{12} \mathrm{M}$ aternal mortality was high but comparable to that reported by Nobis PN $(42.96 \%) .{ }^{12}$ Others have reported less maternal morbidity. Perinatal mortality in this study came out to be $44 \%$ which is quite high but also reported by Gaddi, Somegowda (39.3\%) and $\mathrm{K}$ hanum $\mathrm{M}$ et al $(38 \%)^{5,11}$

In our study, none of the patient threw another fit after receiving loading dose of magnesium sulfate. Same findings were seen by Samal S et al ${ }^{4}$ where as some reported $2 \%$ recurrence rate. ${ }^{7}$

\section{CONCLUSION}

We concluded that there is lack of antenatal care in rural areas and urban slums and this needs to be addressed to prevent this serious complication of pregnancy. The personnel at district hospitals and CHCs should be capable of administering magnesium sulfate. Eclampsia is a largely preventable complication of pregnancy provided the pregnant women get proper health education and regular antenatal care. Toward this goal, early antenatal booking, careful and regular follow-up, knowledge of associated risk factors and an effort to detect this condition early are essential.

A s it is associated are high maternal morbidity and mortality and poor perinatal outcome, so proper management of PIH and timely referral to higher center is important step. The unbooked cases going directly to community centers, civil hospital, and private doctors should be referred after giving preliminary treatment in form of magnesium sulfate, the anticonvulsant as delay in start of treatment means more complication rate.

\section{ACKNOWLEDGMENT}

The author is grateful to Dr H arkiran K aur, Professor and Head, Department of Obstetrics and Gynecology, GGS M edical College and Hospital, for her support and guidance. 


\section{REFERENCES}

1. Tukur J. The use of magnesium sulfate for the treatment of severe preeclampsia. A nn A fr M ed 2009;8(2):76-80.

2. Chandraharan $E$, A rulkumaran $S . M$ anagement of preeclampsia/ eclampsia. IntJ Gyn Obst India 2005;8(1):19-24.

3. Shaheen B, Hassan L, O baid M. Eclampsia, a major cause of maternal and perinatal mortality: A prospective analysis at a tertiary care hospital of Peshawar. J Pak M ed A ssoc 2003;53: 346.

4. Samal S, Gupta U, A garwal P. M anagement of eclampsia with magnesium sulfate and nifedipine. J Obstet Gynecol Ind 2001; 51(3):71-74.

5. K hanum M, A shraf F, Sahrin H. A clinical study of 100 cases of eclampsia in Rajshahi Medical College and Hospital. TAJ 2004;17(2):80-83.

6. Chandra M, Bhardwaj B. Our experience with the use of magnesium sulfate in eclampsia. J Obst Gynecol Ind 1998; 48(2):38-42.

7. Sheraz S, B oota M, Shahzad S. Eclampsia. Prof M ed J 2006; 13(1):27-31.
8. Datta M R, Pant L, Kabiraj M, B asu SB. M agnesium sulfate in eclampsia: A safe, efficient and cost-effective approach. J Obst Gynecol India 2002;52(3):65-68.

9. Sarma HK. A clinical study on eclampsia. A sian J Obst Gyn Pract 1999; 3(4): 43-47.

10. Choudhary P. Eclampsia: A hospital based retrospective study. Kathmandu U niversity M edical J ournal 2003; 1(4):237-41.

11. Gaddi SS, Somegowda. Maternal and perinatal outcome in eclampsia in a district hospital. J Obst Gyn Ind 2007;57(4):324-26.

12. Nobis PN. M aternal outcome in eclampsia. A sian J Obst Gyn Practice 2001;6(1):25-28.

\section{ABOUT THE AUTHOR}

\section{Parneet Kaur}

A ssociate Professor, Department of Obstetrics and Gynecology Government M edical College, Patiala, Punjab, India

CorrespondenceAddress. House N 0. 151, Punjabi B agh, N ear K lair Orthopedic Centre, Patiala-147001, Punjab, India, Phone: 9876726865, e-mail: parneetkd@yahoo.co.in 